\title{
Editorial
}

\section{New Research on Ancient Themes in a New Journal}

\author{
Jaswant S Bhopal* \\ Department of Psychiatry, University of British Columbia, Canada \\ ${ }^{*}$ Corresponding author: Jaswant S Bhopal, Department of Psychiatry, University of British Columbia, Can- \\ ada, Tel: +1 6046163250; E-mail: jasbhopal66@msn.com
}

Received Date: 21 July, 2018; Accepted Date: 28 July, 2018; Published Date: 01 August, 2018

Having been around for 300,000 years [1], our species, Homo sapiens, "thinking man", has enjoyed and suffered a wide spectrum of thoughts and moods, and still does. When these thoughts and moods become dysfunctional, they are labeled as mental disorders. Over the millennia, different treatment approaches, from religious to quasi-scientific, have been employed.

Have these approaches changed substantially? I say not completely. Many modern approaches to the treatment of mental illness still revolve around ancient themes. The scientific contents of this inaugural issue of Norcal's Open Access Journal of Psychiatry and Behaviour Therapy pertain to some of those olden approaches, specifically, pranayama yoga as therapy, dietary patterns, mental diversions, and physical fitness.

The Vedas, the ancient Indian texts of philosophy and wisdom, speak of three sources of suffering [2], and their mitigation. The three sources are adhyātmika (arising from body-mind), adhibhautika (arising from relationships), and adhidaivika (arising from the demigods - the natural environment). No one is immune to these three modes of suffering. Patanjali [3], the ancient sage who wrote the yoga-sutras, the yoga scriptures, posited that suffering can be mitigated by the practice of holistic yoga. The latter discipline aims to diminish suffering and to enhance mental tranquility. In this regard, my Canadian team examined pranayama yoga breathing, and meditation, as a group therapy for a variety of DSM-IV mental disorders. The startling finding that pranayama yoga breathing and meditation have an immediate, beneficial effect is described in this issue.

One more modern approach to the treatment of mental illness that has an ancient basis is mental diversion. We know that positive diversions of the mind can induce calmness. The exciting, modern question is, "Can we use 'high-tech' tools for mental diversion in the treatment of depression?" It seems so. In this issue of the journal, Paltoglou, writing from the United Kingdom, describes the successful use of virtual reality techniques in the therapy of depression.
Yet another modern discussion on the treatment of mental illness has roots in another ancient theme, namely diet and depression. The connection between these is mentioned in Robert Burton's historic book of 1621, "The Anatomy of Melancholy" [4]. He waxed that a "bad" diet could cause melancholy and a "good" diet could cure it. The idea seems plausible but requires modern scientific validation. In this issue of the journal, Zhang revisits the issue. Writing from China, Zhang briefly reviews the international perspective on the role of "good" and "bad" diets and their importance in the treatment of depression.

Another modern discussion on the treatment of mental illness is embedded in another traditional theme, namely exercise and depression. To be sure, exercise and mood are well established as having a positive relationship. However, a question that remains to be fully answered is, "What is the health status of those who practice fitness?" In this inaugural issue of the journal, Kutuzova et al, bring some answers to this question. Writing from Russia, they compare the physical and mental health of female fitness aficionados, both novice and seasoned, both of Russia and Canada. Kutuzova et al report on the BMI measures, satisfaction with bodily appearance, and emotional health of clients attending fitness centers. The authors propose, that while exercise is touted to be good for health, the actual health status of those who exercise for fitness has been under-measured.

I reiterate. Many modern approaches to the treatment of mental illness still revolve around ancient themes. Many of Homo sapiens' ideas of old are still relevant today. However, they require scientific validation. Norcal's Journal of Psychiatry and Behaviour Therapy is helping in the role of validation by "open-access" dissemination of scientific research. Enjoy reading this inaugural issue.

\section{References}

1. What does it mean to be human? Smithsonian National Museum of National History. 
2. Canto 5: The Creative Impetus. SB 5.14: The Material World as the Great Forest of Enjoyment. Bhaktivedantha VedaBase, A Treasure of Spiritual Knowledge.

3. Patanjali's Yoga-Sutra - The Guide of Yoga, with translation and commentary.

4. Katrina Longhurst, Melancholy, diet and Robert Burton, University of Leeds. 